\title{
UNDERGRADUATE WRITING ASSIGNMENTS IN ENGINEERING: SOME PRELIMINARY FINDINGS
}

\author{
Roger Graves ${ }^{1}$, Anne Parker ${ }^{2}$ and Kathryn Marcynuk ${ }^{2}$ \\ ${ }^{1}$ University of Alberta and ${ }^{2}$ University of Manitoba \\ Anne_Parker@ad.umanitoba.ca
}

\begin{abstract}
Based on our compilation of the course outlines from the Departments of Electrical and Computer Engineering, Civil Engineering and Mechanical Engineering, this paper will focus on our preliminary findings. This study - as part of a larger, multidisciplinary project - analyzes how often students write in Engineering courses and, when they do, what genres of documents they are being asked to write. While each department includes writing components, their methods of evaluation are different. Consequently, each department emphasizes writing differently, as exemplified in their different evaluation weightings, and this emphasis has some important implications for the Faculty of Engineering at the University of Manitoba.
\end{abstract}

Keywords: writing assignments, engineering, course outlines, accreditation, attribute 7 , undergraduate

\subsection{INTRODUCTION}

This study resonates in an Engineering school for two very important reasons. First, producing graduates with effective communication skills has increasingly become important, and most schools have diligently worked toward achieving that goal. However, some industry stakeholders complain that our students' communication skills are still weak [1] [2]. Secondly, the Canadian Engineering Accreditation Board (C.E.A.B.) demands that our graduates demonstrate "an ability to communicate complex engineering concepts within the profession and with society at large. Such abilities include reading, writing, speaking and listening, and the ability to comprehend and write effective reports and design documentation, and to give and effectively respond to clear instructions" [3].

To gain insight into how these communication abilities are being developed in the University of Manitoba's engineering program, we gathered data on the assignments our students are being asked to write. We did so by collecting the course outlines from all available core and elective courses offered by the Electrical and Computer, Civil, and Mechanical Engineering departments, and then documenting the inclusion of the C.E.A.B. graduate attribute, "Communication Skills (7)." Typically, engineering students take only a subset of the elective courses. Consequently, the fewest courses that a student can take with the communication attribute (“min.”) - while still fulfilling the requirements of the program - likewise have been indicated, as summarized below:

\begin{tabular}{|l|l|l|l|l|}
\hline & Total & Req'd & Att. 7 & Min. \\
\hline Civil & 34 & 27 & 27 & 19 \\
\hline Computer & 33 & 17 & 21 & 13 \\
\hline Electrical & 33 & 16 & 21 & 11 \\
\hline Mechanical & 33 & 21 & 26 & 11 \\
\hline
\end{tabular}

In this paper, we will first outline the larger study of writing assignments in a wide variety of academic disciplines outside of Engineering. Next, we will outline some of the challenges we faced in undertaking this study. We will then discuss some of our preliminary findings, which indicate that these departments emphasize writing differently. We will then conclude with some observations about what the implications are for the Faculty of Engineering at the University of Manitoba.

\subsection{UNDERGRADUATE WRITING ASSIGNMENTS: THE LARGER STUDY}

This larger study investigates 30 different aspects of undergraduate writing assignments, including how often post-secondary students from a variety of academic disciplines are asked to write [4] [5] as well as what genres (or kinds) of writing assignments they are required to write. Looking at writing assignments across the university curriculum 
is an important undertaking given that even the global community of writing studies researchers may be hard-pressed to describe (or even identify) both the kind and the frequency of writing assignments in our undergraduate schools. Nevertheless, it is crucial that we know as much as we can. Otherwise, we cannot recognize the complexity of developing the literacy levels of post-secondary students. Nor can we remain unaware of what kinds of demands our own programs are placing on students. Without that knowledge, we cannot optimize the way we structure our assignments and support our students as they learn to write the kinds of texts that the faculty member will want to read. In Engineering, that difficulty is compounded by the concomitant demands of the profession, itself a stakeholder in the process of educating engineers who can write effectively.

Therefore, this larger research program provides systematic research about the demands placed on undergraduate students as writers in a wide variety of disciplines, students who currently graduate in record numbers but sometimes without even a basic ability to share or communicate the knowledge they have gained. Their underdeveloped writing skills lead to two possible outcomes, both negative ones; namely, the inability of these students to pursue graduate studies and, if they do go to graduate school, the inability of these programs to divert the resources needed to "fix" this problem. More damagingly, this lack of skills may derail students' efforts to find - and keep - a career in areas related to their academic interest.

To address this complex problem, our research program has two objectives. First, we have begun mapping the writing demands placed on undergraduate students by collecting all the writing assignments given to students in their programs of study so that we can say with certainty just what students are being asked to write. This information has proven to be extremely useful as a catalyst for curriculum review and change because it identifies the goal for discipline-specific student writing. Secondly, we plan to interview students and examine their writing practices and strategies in an effort to uncover how they approach the writing demands set by the curricula described in the first objective. Existing research in writing studies can be used to

CEEA12; Paper 50 identify whether these strategies are effective or counterproductive [6] [7].

Recently, Graves, Hyland and Samuels [4] reported on their analysis of syllabi collected from one college and 17 different departments. Their findings highlighted the variability of writing across the disciplines; for example, a total of 485 assignments were given out in 179 courses in 17 different academic units. However, 3 units required no writing while several others required an average of almost 6 assignments per course. The "nesting" (or linking) of assignments, the assignment genre required and the number of assignments required diverged widely between disciplines.

This approach of collecting course syllabi shows how writing assignments differ even within a specific program at one college and also provides us with a complete picture of writing tasks assigned to students within several programs. This approach likewise shows us how writing tasks can vary widely between disciplines as well. In this important way, this larger study responds to the call from Anson and Dannels [8] that we create program profiles of departments in an effort to map the writing demands we place on our undergraduates and then map these demands onto the curricula. To that end, we need samples of writing assignments collected from whole curricula rather than through convenience samples. We are now endeavouring to do that in the Faculty of Engineering at the University of Manitoba.

\subsection{C.E.A.B. GRADUATE ATTRIBUTE AND UNDERGRADUATE WRITING ASSIGNMENTS}

We faced some major challenges in undertaking this study, primarily because data on the writing content of each assignment were difficult to extract from the course outlines. Most course outlines in Engineering do not explicitly list each assignment, nor do they always describe the type of work required. Rather, the outlines tended to refer generally to "assignments," as well as to lab reports and projects. Each discipline also tended to emphasize assignments in their own way, so that "mini-projects" may have been called "assignments" (not projects). Rather than guessing at what was included in each category, we simply kept the terms 
used by the departments. Because of this constraint, we had to adopt a number of assumptions, including the following:

First, only courses that explicitly identified C.E.A.B. attribute 7 were assumed to have writing components. Secondly, since the work required for the assignments was not included on the course outlines, we assumed that they contained writing components, unless explicitly indicated otherwise. Thirdly, we assumed that all included courses are offered each year to students; concomitantly, any course for which the outline was not available was not included in the analysis. Finally, because most course outlines did not identify the specific type of assignments used for evaluation, we assumed that the genres included would be the usual engineering ones, like lab reports and design projects; tests and exams were not included.

To determine the amount of writing content in each program, we collected course outlines from all available core and elective courses offered in Civil, Mechanical, and Electrical and Computer Engineering. Each outline contained a brief description of the course, the mark breakdown and the learning outcomes mapped to C.E.A.B. graduate attributes. Additionally, we recorded the relative percentage of marks dedicated to the evaluation of assignments, labs and design reports for each course that identified this attribute.

\subsection{Civil Engineering}

The writing components within Civil Engineering are distributed relatively evenly among assignments, labs and projects. As shown, communication skills may be worth over $50 \%$ of the final grade in 3 courses in Civil Engineering, although determining the actual value given to them is problematic.

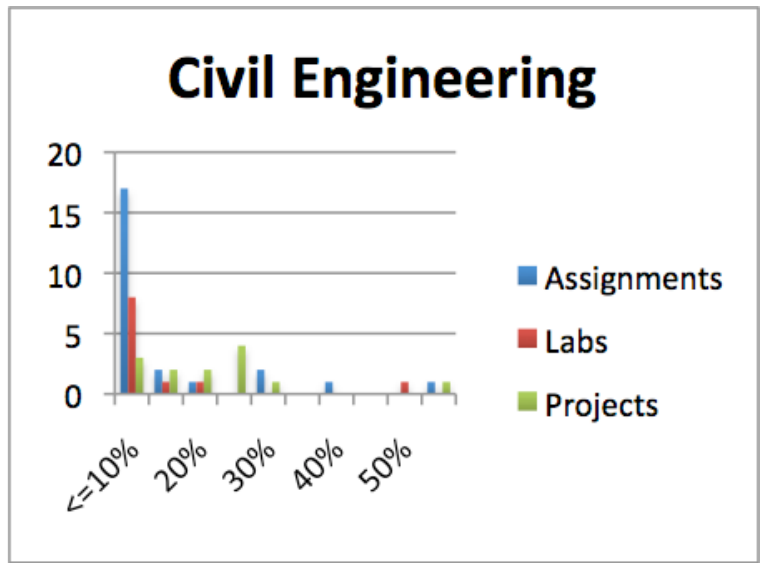

\subsection{Electrical and Computer Engineering}

In both Electrical and Computer Engineering, a much heavier emphasis is placed on labs rather than assignments or projects. As well, most course components with the potential for writing are worth less than $25 \%$ of the final grade. The only course in either discipline with a written component worth over $50 \%$ of the final grade is the senior-year design project class.

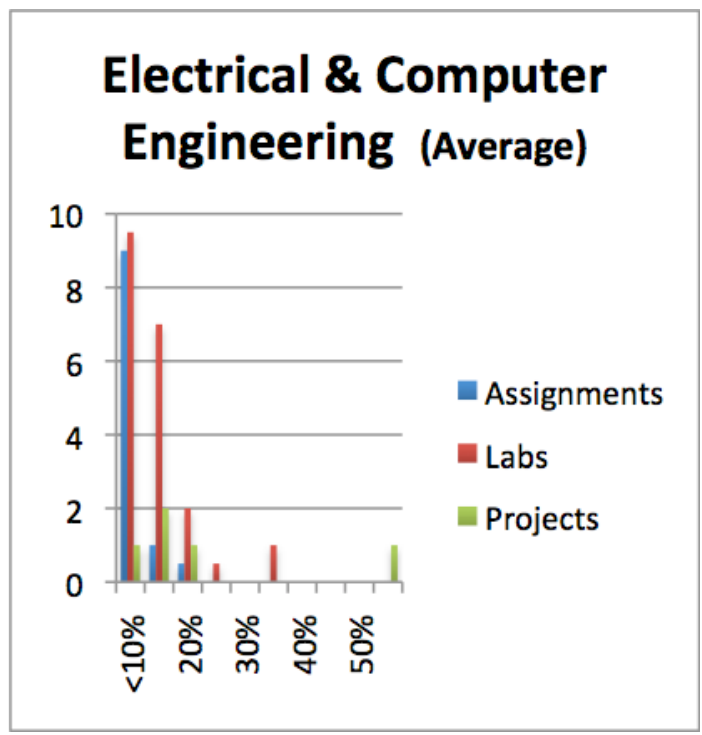

\subsection{Mechanical Engineering}

The majority of Mechanical Engineering classes have projects that include a written component. A striking 22 classes (of a possible 33) have projects worth at least $25 \%$ of the final grade. As well, of all the disciplines, Mechanical Engineering shows the smallest number of courses 
with writing delegated to minor assignments worth $10 \%$ or less. Indeed, Mechanical Engineering has 6 courses in which writing assessment may be worth $50 \%$ or more of the final grade.

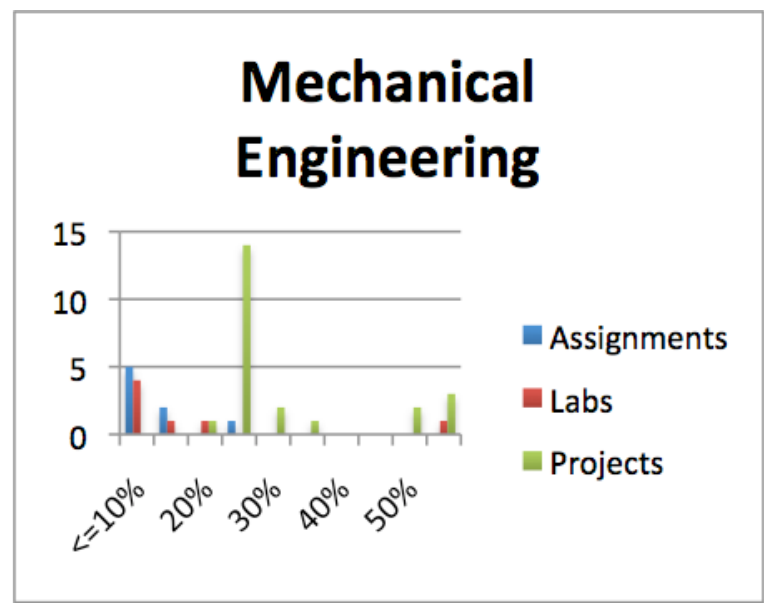

\subsection{SOME OBSERVATIONS, IMPLICATIONS AND PRELIMINARY CONCLUSIONS}

We collected information on each course in the Faculty of Engineering that evaluates communication skills, as defined by the C.E.A.B.'s Attribute 7. Courses were grouped into the departments of Civil, Electrical Computer and Mechanical Engineering. The results from each department can be taken together to form a picture of the average amount of emphasis placed on written communication assignments in the faculty at the undergraduate level. The study showed that each department includes writing components with different methods of evaluation. Additionally, each department also emphasizes writing differently through their course evaluation weightings. Thus, Civil Engineering allots over $50 \%$ of the final grade to the communication component in as many as 3 courses, while both Electrical and Computer Engineering seem to emphasize labs, not written assignments, and have only one, the senior-year design project, where communication is worth over 50\%. It is Mechanical Engineering, however, where the emphasis on the written component seems to be more pronounced.
These are early findings, and much remains to be done. Because the outlines do not describe the kinds of assignments or indicate whether the assignments are "nested" (or linked in any meaningful way), we will now have to approach individual instructors and try to collect this kind of information. Nor do the outlines describe the assignments in any detail; we had problems, for example, identifying whether an assignment was a written assignment or a problem-solving assignment. As well, whether the evaluation is formative or summative is not always indicated, making our task more difficult. One preliminary conclusion to be drawn is assessment continues to be a challenge, both when we try to assess the writing done in a variety of courses across the engineering disciplines [2] and especially when we consider the relative weightings and perceived importance accorded to the technical and written components [9].

Of course, in some sense students face a similar problem when they attempt to identify the writing tasks placed before them: what kind or genre of assignment are they being asked to create? This lack of detail about the genre of the assignment is a widespread problem throughout university syllabi [4] [5] [6]. In important ways the lack of genre or even mis-identification of the required genre is a contributing factor to poor student writing because it slows students down as they attempt to respond to the writing prompt-their first task becomes guessing what kind of a document they should create in response to the writing prompt. The time and effort they waste on this process takes away from time that could be spent researching the topic or editing and proofreading. Students who do not guess correctly about the genre or even about details of the assignment such as how to organize their response produce documents that lack critical criteria and thus do poorly when evaluated.

While the study reported here did not collect information about scoring guides or marking criteria for these assignments, best practices in writing instruction indicate that instructors should make these sorts of guides available to students at the time students receive the writing assignment [10]. We do not know if students in these Engineering courses were given access to the scoring guides or rubrics that would be used for evaluating their written work. 
Evidence from other disciplines suggests that it is unlikely that these were provided [4] [5]. One suggestion we can offer the Faculty as a whole is to provide details about the genre of assignment students must produce and the criteria that will be used to evaluate that assignment in the outlines that instructors distribute to the students at the beginning of the course.

The larger study of analyzing writing assignments across the liberal arts, nursing, pharmacy and physical education suggests that the further students proceed in a discipline of study the more specialized the kinds of writing they will be asked to perform. The study of Engineering disciplines reported here suggests the same pattern is at work. We saw that the way writing is evaluated differs from program to program, and so does the emphasis, with Civil and Mechanical Engineering placing a heavier emphasis on writing in the calculation of grades. This suggests that calls for the improvement of student writing in Engineering programs may need to focus on specific disciplines because there appear to be differences in the amount and kinds of writing within engineering faculties as a whole. Further investigations of the writing demands (expressed in both the kinds of assignments and in how students respond to those assignments) should provide a fuller picture of what causes students in Engineering to develop - or fail to develop - advanced literacy skills.

Funding for this research was provided by the Social Sciences and Humanities Research Council (SRG RES0006514).

\subsection{REFERENCES}

[1] J. Donnell, B.M. Aller, M. Alley and A.A. Kedrowicz. (2011, June]. "Why industry says that Engineering graduates have poor communication skills: What the literature says," in ASEE Conference Proceedings [DVD], Vancouver, B.C., 2011, AC2011-1503.

[2] T.D. Rhoulac and P. Crenshaw. [2006, Oct.]. "Preparing Civil Engineering students to meet workplace writing expectations," in FIE 2006 Proceedings: 36 ${ }^{\text {th }}$ ASEE/IEEE Frontiers in Education Conference [Online], San Diego, CA, 2006, M1H-3 - M1H-7. Available: IEEXplore [May 21, 2012].

[3] The Canadian Engineering Accreditation Board. (2008). Accreditation Criteria and Procedures [Online].

CEEA 12; Paper 50
Available:http://www.engineerscanada.ca/e/files/report_cea b.08.pdf [April 16, 2012].

[4] R.Graves, T.Hyland and B. Samuels, "Undergraduate writing assignments: An analysis of syllabi at one Canadian college," Written Communication, vol. 27 no.3, pp. 293-317, 2010.

[5] R. Graves and S. Chaudoir. (2011, Feb. 7). Writing Assignments in the Community Service Learning Program at the University of Alberta. Available: https://www.humanities.ualberta.ca/WAC_Secure/Publicati ons.aspx [May 14, 2012].

[6] S. Graham, "Strategy instruction and the teaching of writing: A meta-analysis," in Handbook of Writing Research, C. MacArthur, S. Graham and J. Fitzgerald, Eds. New York, NY: Guilford, 2006, pp. 187-207.

[7] R. Haswell. (2008). "Teaching of writing in higher education," in Handbook of Research on Writing: History, society, school, individual, text, C. Bazerman, Ed. NY, NY: Erlbaum, pp. 331-346.

[8] C.A. Anson and D. Dannels. (2009, Dec.3). "Profiling programs: Formative uses of departmental consultations in the assessment of communication across the curriculum." Across the Disciplines: A Journal of Language, Learning and Academic Writing [Online], 6 [Special Issue on Writing Across the Curriculum and Assessment], pp.1-16. Available:

http://wac.colostate.edu/atd/assessment/anson_dannels.cfm [May 22, 2012].

[9] S. Conrad and T.J. Pfeiffer, "Preliminary analysis of student and workplace writing in Civil Engineering," in ASEE Conference Proceedings [DVD], Vancouver, B.C., 2011, AC2011-961.

[10] J. Bean. Engaging ideas: The Professor's Guide to Integrating Writing, Critical Thinking, and Active Learning in the Classroom. $2^{\text {nd }}$ Ed. San Francisco: Jossey-Bass, 2011. 